\title{
ENZYME POLYMORPHISM IN FERAL, OUTBRED AND INBRED RATS (RATTUS NORVEGICUS)
}

\author{
K. ERIKSSON, O. HALKKA*, J. LOKKI* and A. SAURA* \\ Research Laboratories of the State Alcohol Monopoly (Alko), Helsinki, Finland
}

Received 8.iv.76

\section{SUMmary}

Polymorphism at 25 loci coding for liver enzymes was studied in two feral, three outbred and three inbred rat strains by starch gel electrophoresis. No variation was found at $14 \mathrm{loci}$, and a low degree of polymorphism was detected at three. Eight loci were polymorphic in more than one population. The average degree of heterozygosity per locus per individual feral rat was 0.07 .

The degrees of heterozygosity observed in the outbred and inbred strains were lower, from 0.006 to 0.012 . Contrary to expectation, the inbred strains were neither monomorphic nor appreciably less heterozygous than the outbred ones. The heterozygosity of the inbred strains was primarily due to two polymorphic loci, $G-3-p d h$ and $\alpha-G p d h$. The reason for this polymorphism is probably the superior homeostasis of the heterozygotes.

\section{IntRODUGTION}

BroLogists carrying out experiments with laboratory mammals are often troubled by the possibility that their stocks are genetically heterogenous. Laboratory rats and mice are inbred for many generations in the hope that only traces of the original genetic variability will persist. Different alleles may be fixed in different strains. Assuming such chance fixation, how far can we generalise from results derived from selected strains? How much of the total genetic variability of the Norway rat is present in the laboratory populations? These familiar questions (e.g. Eriksson and Närhi, 1973) are of great import for physiological work, which demands extreme homogeneity of test stocks.

Ample data exist on genic polymorphism in laboratory and feral populations of mice. In addition to studies on population genetics, there is a considerable body of literature on single-gene polymorphism and linkage relationships in mice and to a lesser extent in rats. For the rat, only scattered reports are available on enzyme polymorphisms in feral populations, and no estimates of average heterozygosity have been made.

Serov (1972) studied feral Siberian rats and one laboratory strain. He found no evidence of genic polymorphism at the approximately 20 loci investigated and concluded that wild and laboratory populations of Rattus norvegicus seem to be completely devoid of polymorphisms. Serov's results are very different from those obtained for feral and laboratory mice. They are, in fact, quite unexpected for populations of a mobile bisexual species.

The social structures of wild indoor populations of mouse and rat apparently differ. Subdivision into small intimate demes such as may be the rule with mice (Anderson, 1970; Selander, 1970; cf. Myers, 1974) is much less

* Present address: Department of Genetics, University of Helsinki, Finland. 
pronounced with rats. For social reasons, migrations from one rat deme to another do take place, and some of the "demes" may consist of groups of males forced to be almost inactive sexually (Calhoun, 1963). Although large rat colonies may accept immigrants with seemingly trifle social disturbance (Telle, 1966), adverse demographic effects may result from immigration (Davis and Christian, 1956). We feel that, in a comparative sense, the implications of social structure for genetic structure in the mouse and the rat cannot be established on the basis of existing data. Yet the degrees of heterozygosity of these populations may be compared with each other.

Mice and rats have about equally long histories as laboratory animals and hundreds of inbred and outbred strains exist for both. A population inbred for 20 generations is generally considered to satisfy the requirements of an inbred strain. There are no grounds for expecting mice and rats to react dissimilarly when subjected to the standard inbreeding and outbreeding techniques. In discussing polymorphism in the rat, it is necessary to lean heavily on studies on the mouse, since both the wild and laboratory populations of the latter are relatively well known as to their enzyme genetics.

In this study we estimate the degrees of heterozygosity in two feral, three outbred and two inbred populations of the Norway rat. Two of the outbred strains were earlier subjected to antithetical selection procedures in the sense that one (AA) was selected for preference, the other (ANA) for avoidance of alcohol in a free choice situation.

\section{Materials AND MEthods}

\section{(i) Experimental animals}

Adult wild rats were obtained from a storehouse in the Munkkisaari harbour, Helsinki; and from a farmhouse in Janakkala, about $80 \mathrm{~km}$ north of Helsinki. The Munkkisaari sample consisted of 39 rats and the Janakkala sample of 47 rats. The rats were fed in the laboratory for a few days with a high quality laboratory food (from Astra Ewos, Södertälje, Sweden). One female rat gave birth to a litter in the laboratory, whereafter the young were reared into adults.

Three outbred rat strains were analysed. Two of these, described by Eriksson and Närhi (1973) and called AA (Alko, Alcohol strain) and ANA (Alko, Non-Alcohol strain) originated from a conventionally maintained albino laboratory stock of Wistar origin which was then systematically outbred for 24 generations. The population size varied in both strains between 80 and 140 individuals, and about $20-25$ per cent of the population was used for producing the next generation. The third strain, or population, called " mixed ", also originated from the Alko laboratory in Helsinki. Its history is as follows: AA and ANA (Wistar) individuals were crossbred with a conventional albino stock " $\mathrm{KZ}$ ", maintained in Korkeasaari Zoo. This group of crosses included 17 pairs with either $\mathrm{KZ}$ or one of the alcohol strains as the male parent. Ten males or females from the $F_{1}$ offspring population were crossbred with a Sprague-Dawley albino strain (from Anticimex, Sweden). The $\mathrm{F}_{2}$ offspring population was crossbred with randomly outbred strain of Long-Evans hooded rats (from Simonsen Laboratories, Inc., Gilroy, California, U.S.A.). The $\mathrm{F}_{\mathbf{3}}$ progeny population was used in this study. The mixed population originates from the three most widely used rat strains 
(Wistar, Sprague-Dawley and Long-Evans), and presumably contains a large share of the genetic variability of standard laboratory strains. For electrophoresis, 30 adult rats were taken from the AA strain, 32 from the ANA strain and 30 from the mixed strain.

The two inbred strains studied were Fischer $_{344}$, from the Simonsen laboratories, and ACI from the Microbiological Associations, Inc., Walkersville, Maryland, U.S.A. These strains had been inbred about 110 (Fischer) and about 95 (ACI) generations, respectively, with the brother-sister mating method. The sample from the Fischer strain comprised 87 and that from the ACI 71 adult rats. The sex and a description of the general condition of each rat are on record.

Altogether, 337 rats were assayed from the wild, outbred and inbred populations. In addition to these, a single Wistar albino male (from Møllegaard laboratorier A/S, Copenhagen, Denmark) was used as a control throughout the study.

\section{(ii) Laboratory procedures}

The rats were anaesthetised with ether. Small slices of liver tissue were cut off and immediately placed in a deep-freeze container. Subsamples taken from the same piece of tissue at various intervals showed that storage at $-20^{\circ} \mathrm{C}$ for a period of up to 4 months did not have a qualitative effect on the migration and activity properties of the enzymes investigated. Pieces of frozen liver tissue measuring about $1 \mathrm{~mm}^{3}$ were homogenised in a drop of the gel buffer used for each run.

Homogenates were subjected to horizontal starch gel electrophoresis as described by Ayala et al. (1972), with the modification that only "Sigma" starch was used, and the buffer system " $\mathrm{C}$ " (tris-citric acid, $p \mathrm{H} 7 \cdot 0$ ) was substituted for "B". The enzyme assay procedures described by Shaw and Prasad (1970) were followed with some modifications and additions (cf. Saura et al., 1973). For staining glucose-6-phosphate dehydrogenase, $50 \mathrm{mg}$ of NADP was added to the gel prior to degassing. Cyanate was not added to any of the dehydrogenase stains. Malic enzyme was assayed with a stain similar to that used for malate dehydrogenase, but NADP was used instead of NAD and a few drops of a 10 per cent solution of $\mathrm{MgCl}_{2}$ were added per $100 \mathrm{ml}$ of stain.

The following enzymes were assayed successfully: adenylate kinase (Adk, E.C. 2.7.4.3), aldehyde oxidase (Ao, E.C. 1.2.3.1), alcohol dehydrogenase (Adh, E.C. 1.1.1.1), esterase (Est, E.C. 3.1.1.2), fumarase (Fum, E.C. 4.2.1.2), glucose-6-phosphate dehydrogenase (G-6-pdh, E.C. 1.1.1.49), glutamateoxalo-acetate aminotransferase (Got, E.C. 2.6.1.1), glyceraldehyde-3phosphate dehydrogenase (G-3-pdh, E.C. 1.2.2.12), $\alpha$-glycerophosphate dehydrogenase ( $\alpha$-Gpdh, E.C. 1.1.1.8), hexokinase (Hk, E.C. 2.7.1.1), isocitrate dehydrogenase (Idh, E.C. 1.1.1.42), lactate dehydrogenase (Ldh, E.C. 1.1.1.27), malate dehydrogenase (Mdh, E.C. 1.1.1.37), malic enzyme (Me, E.C. 1.1.1.40), phosphoglucomutase (Pgm, E.C. 2.5.7.1), 6-phosphogluconate dehydrogenase (6-Pgdh, E.C. 1.1.1.43), superoxide dismutase (Su) and zanthine dehydrogenase (Xdh, E.C. 1.2.3.2).

Aldolase, phosphatases, hydroxybutyrate dehydrogenase, leucine aminopeptidase and triosephosphate isomerase were also assayed, but frozen liver proved unsuitable for analysis of these enzymes. The results of the successful 
tests were analysed mathematically according to Levene and Dobzhansky (1958).

\section{REsults}

The loci coding for enzymes are designated by an abbreviation of the trivial name of the enzyme, as given in the section "Laboratory procedures". Different loci coding for enzymes catalysing the same reaction are numbered according to increasing anodal migration. When several alleles are found at a locus, they are designated by their respective migration distances (in millimetres), again according to increasing anodal migration. An arbitrarily chosen level is given the value 100. The alleles are designed by superscripts added to the enzyme symbols.

TABle 1

Allele frequencies and observed degrees of heterozygosity in polymorphic loci in two wild populations and five laboratory strains of Rattus norvegicus

\begin{tabular}{|c|c|c|c|c|c|c|c|c|c|c|c|c|}
\hline \multirow[b]{2}{*}{ Population } & \multicolumn{3}{|c|}{ Est-1 } & \multicolumn{3}{|c|}{ Est -2} & \multicolumn{3}{|c|}{ Est-3 } & \multicolumn{3}{|c|}{ Fum } \\
\hline & 100 & 102 & Het. & 100 & 104 & Het. & 95 & 100 & Het. & 100 & 100 & Het. \\
\hline Helsinki & 0.62 & 0.39 & 0.513 & 0.56 & 0.44 & 0.410 & 0.39 & 0.61 & 0.375 & 1.00 & - & - \\
\hline Janak & $0 \cdot 66$ & 0.34 & 0.333 & 0.71 & 0.29 & 0.356 & 0.48 & 0.52 & 0.467 & 0.37 & 0.63 & 0.422 \\
\hline Mixed & 1.00 & - & - & 1.00 & - & - & $0 \cdot 10$ & 0.90 & 1.133 & 0.98 & 0.02 & 0.033 \\
\hline $\mathrm{AA}$ & 0.12 & 0.88 & $0 \cdot 167$ & 1.00 & - & - & - & 1.00 & - & 1.00 & - & - \\
\hline ANA & 0.81 & 0.19 & $0 \cdot 189$ & 1.00 & - & - & 0.02 & 0.98 & 0.031 & 1.00 & - & - \\
\hline Fischer & 1.00 & - & - & $1 \cdot 00$ & - & - & 1.00 & - & - & $1 \cdot 00$ & - & - \\
\hline \multirow[t]{3}{*}{$\mathrm{ACI}$} & 1.00 & - & - & $1 \cdot 00$ & - & - & - & $1 \cdot 00$ & - & 1.00 & - & - \\
\hline & \multicolumn{3}{|c|}{$G$-3-pdh } & \multicolumn{3}{|c|}{$\alpha-G p d h$} & \multicolumn{3}{|c|}{ 6-Pghd } & \multicolumn{3}{|c|}{$X d h$} \\
\hline & 100 & 110 & Het. & 100 & 109 & Het. & 100 & 108 & Het. & 100 & 102 & Het. \\
\hline Helsinki & 0.01 & 0.99 & $0 \cdot 026$ & $1 \cdot 00$ & - & - & 0.08 & 0.92 & 0.051 & 0.99 & 0.01 & 0.026 \\
\hline Janal & 0.56 & 0.44 & $0 \cdot 106$ & 0.97 & 0.03 & 0.064 & 0.92 & $0 \cdot 08$ & 0.022 & 0.98 & 0.02 & 0.044 \\
\hline Mixec & - & 1.00 & - & 1.00 & - & - & 1.00 & - & - & 1.00 & - & - \\
\hline $\mathrm{AA}$ & - & 1.00 & - & 1.00 & - & - & 1.00 & - & - & 1.00 & - & - \\
\hline ANA & 0 & 0 & 0 & 1.00 & - & - & 0.91 & 0.09 & 0.630 & 1.00 & - & - \\
\hline Fische & 0.84 & $0 \cdot 16$ & $0 \cdot 029 *$ & 0.96 & 0.04 & $0 \cdot 058$ & 1.00 & - & - & 1.00 & - & - \\
\hline ACI & 0.88 & $0 \cdot 12$ & $0 \cdot 127$ & 0.99 & 0.01 & 0.014 & $1 \cdot 00$ & - & - & 0.99 & $0 \cdot 01$ & 0.014 \\
\hline
\end{tabular}

* Thirty-four individuals only were studied for $G-3-p d h$. The zeros in ANA strain $G$-3-pdh indicate missing data.

Altogether, 25 enzyme loci were studied. The allelic relationships of some of the genes responsible for different enzyme bands were inferred from apparent cases of segregating alleles in a litter of feral rats and in laboratory strains. The interpretation of $G-3-p d h$ allozyme bands was somewhat difficult owing to the overlap of the broad achromatic band of superoxide dismutase (tetrazolium oxidase). At least some alpha-Gpdh heterozygotes in the Janakkala population escaped notice, so that the level of heterozygosity in this population is probably higher than that indicated in table 1 .

No variation was noticed at the following 14 loci: Adk, Adh, Est-4, G-6-pdh-1, Got, Hk-1, Hk-2, Idh, Ldh-1, Ldh-2, Mdh-1, Mdh-2, Pgm and Su. Three loci, $A o, G-6-p d h-2$ and $M e$, were heterozygous in only one rat, and all other rats were monomorphic and homozygous for the allele designated 100 . One rat in the Janakkala population was an $A o^{97 / 100}$ heterozygote and 
another a $M e^{97 / 100}$ heterozygote in the same population. A single Fischer female was a $G-6-p d h-2^{1001102}$ heterozygote. Est-1, Est-2, Est-3, Fum, G-3-pdh, $\alpha-G p d h, 6-P g d h$ and $X d h$ were all polymorphic in more than one population or strain studied. The pattern of polymorphism at these loci is presented in Table 1.

The number of polymorphic loci, the observed degrees of heterozygosity and the degrees of heterozygosity expected on the assumption of a HardyWeinberg equilibrium are given in the following tabulation.

$\begin{array}{lccc}\text { Population } & \begin{array}{c}\text { Number of } \\ \text { polym. loci }\end{array} & \begin{array}{c}\text { Observed } \\ \text { heterozygosity }\end{array} & \begin{array}{c}\text { Expected } \\ \text { heterozygosity }\end{array} \\ \text { Helsinki } & 6 & 0.056 & 0.065 \\ \text { Janakkala } & 10 & 0.074 & 0.104 \\ \text { Mixed } & 2 & 0.007 & 0.009 \\ \text { AA } & 1 & 0.007 & 0.008 \\ \text { ANA } & 3 & 0.012 & 0.020 \\ \text { Fischer } & 3 & 0.004 & 0.014 \\ \text { AGI } & 3 & 0.006 & 0.010\end{array}$

It should be noted that data for the polymorphic locus $G$-3-pdh are missing from the calculations for the ANA strain.

An inspection of the degrees of heterozygosity shows that the average heterozygosities and the number of polymorphic loci are highest in the wild populations. Of the laboratory strains the inbred and outbred strains are equally polymorphic. The most common allele of a given locus is often, but not always, the same in all populations. Thus the Est-1 ${ }^{102}$ is the most common allele in the AA strain but Est- $3^{95}$ in the Fischer strains. The Fischer and ACI strains and the Janakkala feral populations have $G-3-p d h^{100}$ as the most common allele, whereas the other populations are in practice fixed for $G-3-p d h^{110}$ (data for the ANA strain are lacking). Furthermore, at the Fum and $6-G p d h$ loci the prevalent allele is different in the two wild populations studied.

A further inspection of the degrees of heterozygosity shows that they tend to fall short of those expected on the assumption of a Hardy-Weinberg equilibrium. This is mainly due to unexpectedly few individuals heterozygous at $G-3-p d h$ and $G-6-p d h$. As mentioned in the Materials and methods section, $G-3-p d h$ heterozygotes were often difficult to distinguish from homozygotes owing to the partial overlap of the achromatic superoxide dismutase band. This easily leads to scoring them as $G-3-p d h^{100}$ homozygotes. Moreover, $G-3-p d h^{110}$ homozygotes stain so strongly that they can be seen through the $S u$ band as blue spots. The $S u$ band also affects the analysis of 6 -Gpdh electropherograms.

The decay of heterozygosity caused by inbreeding in different strains is as follows:

$\begin{array}{lcrcc}\text { Strain } & \text { Generations } & \mathcal{N}_{e} & \begin{array}{c}\text { Panmictic } \\ \text { index }\end{array} & \begin{array}{c}\text { Probability } \\ \text { of remaining } \\ \text { heterozygous }\end{array} \\ \text { Fischer } & 110 & 2 & 10^{-10} & 10^{-10} \\ \text { ACI } & 95 & 2 & 10^{-10} & 10^{-10} \\ \text { AA } & 25 & 20 & 0 \cdot 53 & 0 \cdot 8 \\ \text { ANA } & 25 & 20 & 0.53 & 0 \cdot 8\end{array}$


The effective population sizes are, of course, accurately known in this study. The probability that heterozygosity would be preserved by change in an inbred strain is negligible. The fact that both strains are about as heterozygous as the outbred strains indicates that some agency has been maintaining heterozygosity in these strains.

It is evident that different loci respond to inbreeding in a dissimilar fashion. Esterases as a group are fairly polymorphic in the wild populations, but their high level of heterozygosity disappears with inbreeding. On the other hand, the $G-3-p d h$ and $\alpha-G p d h$ loci, which are functionally related to each other, remain polymorphic in the inbred strains. In fact, $G-3-p d h$ is clearly more polymorphic in them than in either the outbred strains or the wild populations. The $G-3-p d h$ and $\alpha-G p d h$ loci did not segregate in the Mendelian progenies analysed by us.

\section{Discussion}

The degrees of heterozygosity observed in the two feral populations were 0.056 and 0.074 . The corresponding values expected on the assumption of a Hardy-Weinberg equilibrium are 0.065 and 0.104 , respectively. Of the 25 loci studied, in these two populations, six and ten loci respectively were found to be polymorphic. These results are in striking contrast with the outcome of the work by Serov (1972) on about 20 enzyme loci in Siberian feral rats. The observed total absence of polymorphism in the population studied by Serov was perhaps due to some social restrictions on mating and/or to the founder principle.

The degree of heterozygosity we have observed here is of the same order of magnitude as that Selander and his colleagues found for the mouse. Their figures vary between 0.056 and 0.110 (Selander and Yang, 1969; Selander et al., 1969). Further, Petras et al. (1969) and Ruddle et al. (1969) have obtained similar figures for feral mice. The amount of heterozygosity we observed for feral rats is representative of vertebrates in general (cf. Powell, 1975).

Some of the polymorphisms found in this study have been described earlier. Carter and Parr (1969) screened a large sample of British feral rats for polymorphism at the 6-Pgdh locus and found the frequency of the slower allele (possibly identical with our $6-P g d h^{100}$ ) to range from $0 \cdot 0$ to $0 \cdot 25$. Koga et al. (1972) found that the degrees of heterozygosity at this locus were considerably higher in Japan than in Britain. They also noticed extensive polymorphism at the Pgm locus, which has been studied and reported monomorphic by Carter and Parr (op. cit.) and by us. In addition, Serov and Manchenko (1974) report on polymorphism at the 6-Pgdh locus in Siberian feral populations and in some laboratory strains.

Holmes and Masters (1967) have shown that the multiple rat esterases are controlled by at least 13 structural genes. They also described the occurrences of different esterases in different organs and at different stages of growth in young rats. The liver esterase pattern is stable after the age of 3 weeks. Womack (1973) and Moutier et al. (1973) found linkage between four esterase loci in the rat-a condition that also could be inferred from some of our results. Jimenez-Martin and Dessauer (1973), in addition to having detected variability in esterases, have further described polymorphism of 
alkaline phosphatase and glucose-6-phosphate dehydrogenase in laboratory strains.

The polymorphisms we have detected at the rat Fum, G-3-pdh, $\alpha-G p d h$ and $X d h$ loci have probably not been described before. It is unfortunate that some of the $\alpha$-Gpdh polymorphism probably escaped notice, for this enzyme appears to be polymorphic in the inbred strains. In all probability the degrees of heterozygosity reported for this locus are slightly low.

The fact that the Helsinki harbour rats were less heterozygous than the Janakkala farm rats may appear surprising. One explanation is that since both populations are periodically decimated by poisoning, there may have been a greater (and/or more recent) bottleneck in the Helsinki population (cf. Nei et al., 1975). Another possibility is that gene flow into the Janakkala population is more efficient.

The discovery of genic polymorphism in inbred lines of rats is unexpected. Inbred lines of mice are reported to be monomorphic and to have allele contents that are characteristic of individual strains (Roderick et al., 1971; Taylor, 1972). The inbred strains studied here have two polymorphic loci $(G-3-p d h$ and $\alpha-G p d h)$ and differ with regard to two additional loci. At the Est-3 locus, Est- $3^{95}$ is fixed in the Fischer strain and Est- $3^{100}$ in the ACI strain. The $X d h$ locus is monomorphic in the former strain and polymorphic in the latter.

The combination of strains fixed for different alleles should result in outbred populations which, at least theoretically, are as polymorphic as any feral population. Evidence supporting this conclusion is presented by Roderick et al. (1971) and Taylor (1972) in the context of differences found between inbred mouse strains. These authors suggest that the differences are due to multiple origins of the laboratory strains of Mus musculus.

The history of the domestication of Rattus norvegicus has been reviewed by Castle (1947) and Robinson (1965). According to them, existing laboratory populations are probably of multiple origin. In rats, feral populations clearly have different allele frequencies at many loci, in a fashion analogous to that found in mice. But according to our limited data, inbred and outbred strains are not appreciably different, and combining strains of common origin should not result in extensive heterozygosity. Further research is obviously needed to elucidate how widespread polymorphism is in inbred rat strains.

The decay of heterozygosity in the Fum, 6-Pgdh and in the various Est loci is as expected. Many of the rat esterase gene loci appear to be linked (Moutier et al., 1973; Womack, 1973). The genuineness of the $X d h$ heterozygote in the ACI strain (table 1) is in doubt, since its appearance in the gel was slightly different from that of the feral $X d h$ heterozygotes.

The polymorphism at the $G-3-p d h$ and $\alpha-G p d h$ loci in the inbred strains remains to be explained. These loci code for functionally related enzymes of the primary energy metabolism, and one may speculate that they are subjected to somewhat similar controlling systems. If the polymorphism detected in the two inbred strains at these loci exists as an established condition, then it obviously represents a balanced system. Such a balanced system probably has its basis in some essential alternative states of the metabolism of the liver.

Outbreeding techniques do not seem to be very effective in maintaining or increasing heterozygosity in laboratory rats. It is true, of course, that some inbreeding is unavoidable if an outbred laboratory stock is maintained at a 
moderate population size. The low number of polymorphic loci in the " mixed" strain indicates that the three laboratory strains most commonly used in breeding programmes are quite similar.

Only slight differences were found between the two outbred strains selected for high voluntary alcohol intake (AA) and avoidance of alcohol (ANA). It is true that AA was more monomorphic than ANA, but a physiological explanation of this difference cannot be provided before further study.

Acknowledgments.-Mr Heikki Henttonen, B.Sc., participated very effectively in the work on the feral populations. The processing of the wild and laboratory rats for electrophoresis was performed by Mrs Marie-Louise Virsu, M.A., Mrs Liisa Halkka, Lic. Phil., and Mrs Veronica Söderlund. Mrs Riitta Hovinen, M.A. aided in some later phases of the work. The English of the manuscript was checked by Mrs Kathleen Ahonen.

The study has been financed by grants from the Science Research Council (Academy of Finland), the Finnish Foundation for Alcohol Studies and the Cultural Foundation of Finland.

\section{REFERENCES}

ANDERSON, P. K. 1970. Ecological structure and gene flow in small mammals. Symp. Zool. Soc. London, 26, 299-325.

AYAlA, F. J., POWELl, J. R., TRACEY, M. L., MOURAO, C. A., AND PEREZ-SALAS, s. 1972. Enzyme variability in the Drosophila willistoni group. III. Genic variation in natural populations of Drosophila willistoni. Genetics, 70, 113-139.

calhoun, J. в. 1963. The ecology and sociology of the Norway rat. U.S. Department of Health, Education, and Welfare, Public Health Service Publication No. 1008, 1-100.

CARTER, N. D., AND PARR, c. W. 1969. Phosphogluconate dehydrogenase polymorphism in British wild rats. Nature, 224, 1214.

castle, w. E. 1947. The domestication of the rat. Proc. Nat. Acad. Sci., 33, 109-117.

DAVIS, D. E., AND CHRIsTian, J. J. 1956. Changes in Norway rat populations induced by introduction of rats. F. Wildlife Management, 20, 378-383.

ERIKSSON, K., AND NÄRHI, M. 1973. Specially selected rat strains as a model of alcoholism. In The Laboratory Animal in Drug Testing. 5th ICLA Symposium, Hannover 1972, ed. Arnold Spiegel, pp. 163-171. Gustav Fischer Verlag, Stuttgart.

HOLMES, R. S., AND MASTERs, C. J. 1967. The developmental multiplicity and isoenzyme status of rat esterases. Biochim. Biophys. Acta, 146, 138-150.

JIMENEZ-MARTIN, D., AND Dessauer, H. 1973. Protein phenotype variation in laboratory populations of Rattus norvegicus. Comp. Biochem. Physiol., 46B, 487-492.

KOGA, A., HARADA, s., AND OMOTO, к. 1972. Polymorphism of erythrocyte 6-phosphogluconate dehydrogenase and phosphoglucomutase in Rattus norvegicus in Japan. $\mathcal{F} a p$. $\mathcal{F}$. Genet., 47, 335-338.

LEVENE, H., AND DOBZHANSKY, TH. 1958. New evidence of heterosis in naturally occurring inversion heterozygotes in Drosophila pseudoobscura. Heredity, 12, 37-49.

MOUTIER, R., TOYAMA, K., AND CHARRIER, M. F. 1973. Evidence for linkage between four esterase loci in the rat (Rattus norvegicus). Biochem. Genet., 9, 109-115.

MYERs, J. H. 1974. Genetic and social structure of feral house mouse populations on Grizzly Island, California. Ecology, 55, 747-759.

NeI, M., MARUYAMA, T., AND CHAKRABORTY, R. 1975. The bottleneck effect and genetic variability in populations. Evolution, 29, 1-10.

PETRAS, M. L., ReIMER, J. D., BIDDle, F. G., MARTin, J. E., AND linton, R. s. 1969. Studies of natural populations of Mus. V. A survey of nine loci for polymorphisms. Canad. F. Cytol., 11, 497-513.

POWELL, J. R. 1975. Protein variation in natural populations of animals. Evolutionary Biology, 8, 79-119.

robinson, R. 1965. Genetics of the Norway Rat. Pergamon Press, London.

RODERICK, T. H., RUDDLE, F. H., CHAPMAN, V. M., AND SHOWs, T. B. 1971. Biochemical polymorphisms in feral and inbred mice (Mus musculus). Biochem. Genet., 5, 457-466.

RUDDLE, F. H., RODERICK, T. H., SHOWS, T. B., WEIGL, P. K., GHIPMAN, R. K., AND ANDERSON, P. K. 1969. Measurement of genetic heterogeneity by means of enzyme polymorphisms in wild populations of the mouse. $\mathcal{F}$. Hered., 60, 321-322. 
SAURA, A., LAKOVAARA, s., LOKKI, J., AND LANkinen, P. 1973. Genic variation in central and marginal populations of Drosophila subobscura. Hereditas, 75, 33-46.

SELANDER, R. K. 1970. Behavior and genetic variation in natural populations. $A m$. Zoologist, 10, 53-66.

SELANDER, R. K., HUNT, w. G., AND YANG, s. y. 1969. Protein polymorphism and genic heterozygosity in two European subspecies of the house mouse. Evolution, 23, 379-390. SELANDER, R. K., AND YANG, S. Y. 1969. Protein polymorphism and genic heterozygosity in a wild population of the house mouse (Mus musculus). Genetics, 63, 653-667.

SEROV, O. L. 1972. Monomorphic state of some structural genes in populations of wild and laboratory rats (Rattus norvegicus). Dokl. Akad. Nauk. SSSR, 204, 978-979 (in Russian). SEROV, O. L., AND MANCHENKo, G. P. 1974. Genetic control of electrophoretic variants of 6-Phosphogluconate dehydrogenase (6-Pgd) in wild and laboratory rats. Genetika, 10, 49-56 (in Russian).

SHAW, C. R., AND PRASAD, R. 1970. Starch gel electrophoresis of enzymes-a compilation of recipes. Biochem. Genet., 4, 297-320.

TAYLOR, B. A. 1972. Genetic relationships between inbred strains of mice. 7. Hered., 63, 83-86.

TELLE, H. J. 1966. Beitrag zur Kenntnis der Verhaltensweise von Ratten, vergleichend dargestellt bei Rattus norvegicus und Rattus rattus. Z. Angew. Zool., 53, 129-197.

wOMACK, J. E. 1973. Biochemical genetics of rat esterases: polymorphism, tissue expression, and linkage of four loci. Biochem. Genet., 9, 13-24. 